\title{
Vertical Administration Structure and the Scale of Fiscal Expenditure of Local Government
}

\author{
Sheng Xiaoli \\ Nanchang Institute of Science and Technology, Nanchang, China
}

Keywords: vertical administration structure; local government; the scale of fiscal expenditure

\begin{abstract}
At present, in order to adapt to basic situation of social development in the new era, the Chinese government actively carries out the reform of modern political structure, transforms its functions, and better serves the people. The hierarchical design of the government itself and scientific and reasonable vertical administration structure is the important foundation to guarantee the reform results. In the later stage of the reform and opening-up, the Chinese government carried out two administrative system reforms of city governing county and province governing county. The government power was re-distributed at different levels. This measure affected local economic development and the overall scale of fiscal expenditure of local government. Therefore, relative departments shall conduct in-depth research on vertical administration structure and the scale of fiscal expenditure of local government, so as to make greater development in the new era.
\end{abstract}

In order to deeply study the influence of vertical administration structure and the scale of fiscal expenditure of local government on local economic development, research staff adopt relative data resources of prefecture-level cities, and deeply analyze the impact of the reform of city governing county and province governing county on the overall scale of government fiscal expenditure. The results show that the reform of province governing county has a greater impact on the overall scale of fiscal expenditure, compared with the impact from vertical administration structure of city governing county. Different kinds of reforms will result in a certain difference in the overall scale of fiscal expenditure. The lack of reasonable management and constraint in fiscal expenditure will easily cause the over expansion of fiscal expenditure in government departments in city and county.

\section{The Institutional Background of Vertical Administration Structure Reform}

Since the establishment of People's Republic of China, China's local government departments have long implemented the province, district, and county management system. As a provincial agency, the district has not been given practical management power. Thus, many districts have begun the pilot project of city governing county, but the province governing county still occupies the dominant status. With the rapid development of Chinese economy, the agricultural society has gradually transformed to the industrial society, with the increase of various resource circulations between urban and rural areas. In 1982, the Chinese government began to comprehensively implement the administration institution of city governing county. At present, there are already thousands of city governing county in the whole country. After the reform, prefecture-level city became the main administrative level in province and county. [1]

According to actual situations, in the reform, different reform strategies are taken in different regions. Specific reform modes include the new city leading country, old city leading new county, district changing to city, and the merging of district and city. The new city leading county is the reform mode of certain county-level city or country upgrading to prefecture-level city. The old city leading new county is to join several new counties in the area where the system of city governing county has been implemented, or to join several counties in province or municipality. The model of district changing to city is to transform the previously established district into prefecture-level city. The mode adopted by the merging of district and city is similar, revoking the administrative functions of district, to be included in prefecture-level city. [2]

In the reform of city governing county, the running-in problem between the administrative region 
and the economic region has been initially resolved, the situation of local protection has been improved, the regional market has been gradually unified, the circulation of urban and rural resources has been accelerated, and the complementary advantages have been complemented. The revocation can effectively improve the overall efficiency of local government departments' fiscal expenditures. To carry out public services in some vast and populous areas, and provide various public goods can promote the realization of scale economy. Through reforms, the municipal government has mastered the financial management power and social economic power, and the initiative of the county-level government departments has declined. In the process of implementing the city governing county system in some economically backward areas, many cities with limited economic strength cannot promote the county-level regional economic development, the increase in administrative levels has also led to a decline in the efficiency of information transmission and an increase in administrative costs. At present, prefecture-level city has increased the interference and unwarranted diversion of county-level government resources, projects, and finances. In many areas, serious financial difficulties have arisen. For this reason, many regions have begun to implement the province governing county system and return relevant powers to the county government. The main contents of the province governing county include the province governing county fiscally and the strong county empowerment, transferring the economic and social management power of the municipal government directly to the county government, including construction management, price management, project declaration and approval, legal service supervision, public safety management, quality and technical supervision, medical and health services, etc. The province governing county fiscally is to solve payment transfer, capital transactions, budget and final accounts, and revenue and expenditure division through the direct communication between province and county. Through this reform measure, the power and financial power are decentralized to achieve the optimal allocation of public resources, solve various difficulties in the county-level financial situation, improve the efficiency of government departments, and promote coordinated economic development before urban and rural areas. The redistribution of power between different government agencies can affect the basic efficiency of public services, can also affect the cost of information transmission and management, and can also change the constraint mechanism of government departments. The model of city governing county has strengthened the regional authority of the municipal government. The various financial expenditures are concentrated in the municipal departments. The mechanism of province governing county and the coexistence of city and county will lead to the problem of non-cooperation of the municipal government. Therefore, the research on the influence and action mechanism of vertical administration system and the overall scale of fiscal expenditure has profoundly practical significance.

\section{The Progress of Research on Vertical Administration Structure Reform and the Scale of Fiscal Expenditure}

To build a modern government and realize the transformation of the functions of government agencies requires scientific and reasonable design of the vertical administration system to promote the modernization of national comprehensive governance. In 1982, the Chinese government began to conduct the system reform on the city governing county. In 2003, the government implemented the system reform on the province governing county. Each reform fully integrated the actual situation of social and economic development at that time, with the aim of improving the administrative efficiency of government departments and promoting the economic development in that region. The mode of city governing county recovers the social and economic management power and fiscal power of the county-level government, and divides the entire province into a number of administrative areas with relatively large areas. Under this model, the population and regional area of the area increase. On the contrary, as for the model of province governing county, the power of the municipal government was delegated to the county-level government, and the coexistence of city and county was formed in the region, and the population and regional area decrease significantly. [3]

An important indicator for measuring the overall quality capacity of government departments is 
the scale of fiscal expenditure. Under the system of city governing city, the effect of scale economy is significant. The rapid growth of the population has increased the efficiency of public goods utilization, and the cost of government products has decreased, but information transmission link increases, the overall efficiency of the government declines, the communication cost increases, and the problem of information asymmetry easily occurs. The expansion of the regional area can reduce competition to a certain extent, cooperation in various regions is strengthened, and the total economic volume can be increased at a high speed. The model of province governing county is on the contrary. The jurisdiction of the provincial government law in this mode significantly increases, and the management cost will also rise. Therefore, it is necessary to adopt a reasonable model to study the changes in the scale of fiscal expenditure under different administration systems.

\section{Research Method}

\subsection{Measurement method and empirical model}

The research staff process the province governing county reform and city governing county reform as experiment, and conduct the analysis and verification on the results with DID mode. The specific research mode isy ${ }_{i t}=\alpha_{0}+\alpha_{1}$ reform $_{i t}+\beta_{\mathrm{k}} X_{\mathrm{kit}}+\theta_{\mathrm{i}}+\lambda_{\mathrm{t}}+\Phi_{\mathrm{it}}+\varepsilon_{\mathrm{it}}$, wherein, reform $\mathrm{it}_{\text {it }}$ iseform dummy variable; $X_{\text {kit }}$ is other control variable affecting government scale; yit is the scale of government fiscal expenditure, which is 0 if the region i did not perform the reform in the year of t, otherwise, it is 1 . In the actual research process, the researchers selected per capita fixed asset investment, tertiary industry proportion, per capita savings, per capita GDP, and urbanization rate as the main research indicators, in order to effectively control the differences between national policies and government departments planning in different periods. A cross-fixed relationship $\Phi$ it has been added in the model.

The proportion of per capita fiscal expenditure and government departments' fiscal expenditure to GDP are important indicators for measuring fiscal expenditures. Different reform contents and reform models will have a greater impact on the achievements of the final reform. In the research process, it is necessary to combine actual conditions. In the research process, it is necessary to set dummy variables for the four different situations of the system reform of city governing county. For example, the model of old city leading new county is implemented in a city, the dummy variable is 1 , and the lack of implementation is 0 , so as to verify the results of the overall reform. The research method of province governing county is similar. The research selected the data with a relatively large time span, so there will be a large fluctuation range for many variables, and there are large differences in the data at different times. Therefore, it is necessary to adopt an appropriate adjustment strategy for the decision value variable, and use the logarithm to process the number of per capita fiscal expenditure and the regression of variables. [4]

\subsection{Data statistics}

The data selected by the study mainly came from the documents of the provincial governments and the data provided by the central competent authority. During the research, samples of the city specifically designated in the state plan and autonomous regions, Hainan Province were taken out, and the sample of some prefecture-level cities such as Zhejiang and Ningxia were also deleted. Since the data resources mainly depend on the documents of the government departments, they are relatively scattered. Through analysis and comparison, the data of 2000-2014 and the data of 1980-2003 are selected for research. [5]

\section{Research Results}

\subsection{Common Trend Test and basic regression results}

The premise of using the DID method is to perform the common trend test on the data. For the differences in the reform time of each region, the common trend model isy $_{\text {it }}=\alpha_{0}+\alpha_{1}$ reform $_{\text {it }}+\beta_{\mathrm{k}} \mathrm{X}_{\mathrm{kit}}+\theta_{\mathrm{i}}+\lambda_{\mathrm{t}}+\Phi_{\mathrm{it}}+\varepsilon_{\mathrm{it}}$, wherein, there is at least one significant difference in 
reform $_{\mathrm{it}}$, reform $_{\mathrm{it}+1}$ and reform $\mathrm{it+2}$. The research mode of DID shall fully satisfy the common trend theory. There are obvious differences in the types of reforms adopted in different regions. In the study, the proportion of fiscal expenditure to GDP and per capita fiscal expenditure are important explanatory variables, and the validity of regression can be guaranteed in different equations.

\subsection{The research results of city governing county reform}

Different types of reform models of city governing county can reduce the overall scale of government departments' fiscal expenditures, but the effect is not ideal. The impact of different reform methods on fiscal scale expenditure is quite different. The reform model of old county leading new county has a limited impact on the proportion of fiscal expenditure to the overall GDP, but it can significantly reduce per capita fiscal expenditure. The model of district changing to city has no obvious impact on the overall scale of government fiscal expenditure. The reform model of new city leading the county will cause an increase in the proportion of fiscal expenditure to GDP, which will also increase per capita fiscal expenditure. There is the problem of insufficient urban management experience in the reform mode of new city leading the county. Its own economic strength cannot play a role in stimulating regional economic development. Due to problems in coordination management and decision-making, the scale of government fiscal expenditure will be expanded. [6] The reform model of the merging of district and city is adopted, the districts set up by the provincial departments will be abolished. The economic development level of major urban area in this model is relatively mature, and it is the center of politics, economy and culture in the region. The cost of reform is relatively low. It can significantly promote the economic development of the surrounding areas. When carrying out reforms, it is necessary to set up special rural management institutions, establish a sound large-area management system, and form the interests of scale economy within the region.

\subsection{The research results of province governing county}

The study shows that the reform mode of province governing county significantly increases the expenditure of local government departments. Under this model, the coordination and restraint mechanism of prefecture-level governments has been weakened to a certain extent, and the difficulty of provincial government departments has gradually increased. After the reform, the provincial government needs to directly govern a large number of county-level governments. Due to the insufficient contact with the county-level government, there is certain disadvantages in terms of information and the provincial departments cannot effectively constrain the county and municipal departments economically and fiscally. The excessive expansion of fiscal policy easily occurs, resulting in excessive expansion of extra-budgetary funds such as financing platforms and land transfer fees in city and county government departments. After the reform of province governing county, the county-level government replaced the municipal government, responsible for providing public goods and various services within the region. Due to the relatively small area of the county-level government, it cannot form effective economies of scale, leading to the significant increase in the overall expenditure of government departments. At the same time, the study shows that, the impact of the reform measure of the strong county empowerment on the scale of fiscal expenditure is less than strong county empowerment, and the result of fiscal expenditure in GDP is similar. The strong county empowerment can decentralize the rights of social management and economic planning. However, the fiscal power of the municipal government still exists, and the model of the province governing county is different. The provincial government directly connects with the county-level finance, and the municipal government's fiscal power is seriously weakened. In this model, the competition between different counties and between cities and counties will increase significantly, especially in economic and financial competition. For this reason, many government departments will expand sources of funds through various channels, and increase the investment in economic development, and the overall scale of fiscal expenditure will inevitably increase. 


\section{Suggestions on Vertical Administration Structure and the Scale of Fiscal Expenditure}

With the changes in the social and economic development situation, China has begun to implement a large-scale system reform of village-dismiss and town-combination, county-dismiss and district-establishment, and province governing county. The local administration system under the provincial department has undergone major changes. In areas with different populations and overall areas, various public powers have been re-allocated, and the incentive system of the county and municipal governments has undergone profound changes. The research shows that after the implementation of province governing county, the scale of fiscal expenditure in district and municipal regions continuously increases. The finance is the foundation of national economic development. In order to solve the increase in administration cost brought by province governing county and the development of regional economic scale, it is necessary to actively build up the development mode of province-shrinking and county-combination, and constantly adjust the relationship between governments. To avoid the vicious competition and repeated construction between county and district, it is required to actively transform assessment model with fiscal expenditure and GDP as indicators, strengthen regional cooperation and continuously optimize the incentive mechanism. To promote the development of economically backward regions, and avoid the negative impact of the reforms, it is feasible to reasonably control the speed of reforms and gradually improve various reform measures. [7]

\section{Conclusion}

The finance is the important foundation of national economic development. To improve people's living standard, China vigorously implement the reform of administration structure. In terms of various problems in the reform, relative departments shall strengthen the research, formulate better measures, intensify the cooperation and communication between county and district, and promote the sustainable and healthy development of local economy.

\section{References}

[1] Ding Weirong, Zhang Fan. Will General Transfer Payment System be Partial to Welfare Services Expenditure of Local Government? [J]. Collected Essays on Finance and Economics, 2018(10):19-28.

[2] Zheng Zhengming. Problems and Suggestion of China's Fiscal Expenditure Structure Optimization -From the Perspective of Scientific and Technological Innovation [J]. Shanxi Finance and Tax, 2018(08):31-33.

[3] Zhao Na, Wu Hailan. China's Fiscal Expenditure Structure: Review and Evaluation -Based on Literature Analysis of CSSCI Database in 2002-2017 [J]. Finance \& Economy, 2018(10):26-28.

[4] Tao Chunhai, Wang Yuxiao. The Impact of Government Health Expenditure on Personal Health Expenditure: An Empirical Analysis Based on the Perspective of Total and Structural Effects [J].

Statistics \& Information Forum, 2018,33(05):33-38.

[5] Yu Yangkui. Analysis and Improvement Measures of the Difference in Municipal Fiscal Expenditure Efficiency Based on TOBIT -Taking Zhanjiang, Guangdong Province as an Example [J]. Finance Supervision, 2018(08):80-86.

[6] Li Ronghua, Wang Wenjian. The Impact of Local Government Decentralization Reform on Welfare Public Services -An Analysis on the Decentralization Reform of "Province Governing County” in Henan Province [J]. Socialism Studies, 2018(02):65-76.

[7] Wu Dingwenye, Yang Yun, Li Yushuang. Will Fiscal Expenditure Structure Affect Economic Fluctuation? -An Empirical Analysis Based on Panel Data of Provinces in China [J]. Finance and Economy, 2017(11):39-49. 